\title{
Literaturbericht »Theologie der Religionen« (II)
}

\author{
Reinhold Bernhardt
}

\section{Entwürfe bekenntnisorientierter Religionstheologien}

Horst Bürkle, Der Mensch auf der Suche nach Gott - die Frage der Religionen. Bonifatius, Paderborn 1996, 254 S. - Gerhard Gäde, Christus in den Religionen. Der christliche Glaube und die Wahrheit der Religionen. Schöningh, München 2003, 192 S. - Gerhard Gäde, Viele Religionen - ein Wort Gottes. Einspruch gegen John Hicks pluralistische Religionstheologie. Gütersloher Verlagshaus, Gütersloh 1998, 404 S. - S. Mark Heim, Salvations. Truth and Difference in Religion. Orbis Books, Maryknoll, N.Y. 1995, X + 242 S. - S. Mark Heim, The Depth of the Riches. A Trinitarian Theology of Religious Ends. W. B. Eerdmans, Grand Rapids 2001, XI + 312 S. Veli-Matti Kärkкёinen, An Introduction to the Theology of Religions. Biblical, Historical and Contemporary Perspectives. InterVarsity Press, Downers Grove, Ill. 2003, 372 S. - Karl-Heinz Menke, Die Einzigkeit Jesu Christi im Horizont der Sinnfrage. Johannes, Einsiedeln / Freiburg 1995, 180 S. - Gerhard Ludwig Müller / Massimo Serretti (Hgg.), Einzigkeit und Universalität Jesu Christi. Im Dialog mit den Religionen (Sammlung Horizonte 35). Johannes, Einsiedeln / Freiburg 2001, 294 S. - Dennis L. Oкноlм / Тiмотнy R. Phillips (Hgg.), More than One Way? Four Views on a Salvation in a Pluralistic World. Zondervan, Grand Rapids 1995, 283 S. - Ralph Pechmann / Martin Reppenhagen (Hgg.), Mission im Widerspruch. Religionstheologische Fragen heute und Mission morgen. Neukirchener Verlag, Neukirchen-Vluyn 1999, 462 S. - Ralph Pechmann / Martin ReppenhaGeN (Hgg.), Zeugnis im Dialog der Religionen und der Postmoderne. Neukirchener Verlag, Neukirchen-Vluyn 1999, 256 S. - Edward Rommen / Harold Netrand (Hgg.), Christianity an the Religions. A Biblical Theology of World Religions. William Carey, Passadena, CA 1995, 274 S. - Thomas Schirrmacher (Hg.), Kein anderer Name. Die Einzigartigkeit Jesu Christi und das Gespräch mit nichtchristlichen Religionen (FS P. Beyerhaus). Verlag für Theologie und Religionswissenschaft, Nürnberg 1999, 532 S. - Thомаs D. Sелот (Hg.), The Rationality of Belief and the Plurality of Faiths. Cornell University Press, Ithaca 1995, X + 291 S. - George Sumner, The First and the Last. The Claim of Jesus Christ and the Claim of Other Religious Traditions. W. B. Eerdmans, Grand Rapids 2004, 219 S. - Amos Yong, Beyond the Impasse. Toward a Pneumatological Theology of Religions. Baker Academic, Grand Rapids 2003, 205 S.

Die Bezeichnung »bekenntnisorientiert« wird hier wertfrei im weiten Sinn zur zusammenfassenden Umschreibung einer theologischen Orientierung verwendet, die in sich sehr vielfältig und differenzierungsbedürftig ist. Sie umfasst das weite Spektrum von protestantisch-bibelzentrierten Theologien 
über charismatisch-geistzentrierte Ansätze bis hin zu Positionen, die auf die römisch-katholische Kirche, ihre Lehre und Tradition ausgerichtet sind, sofern sie die exklusive oder superioritäre Stellung der in Christus / in der biblischen Überlieferung / in der Begabung mit dem Geist Christi / in der Kirche vermittelten Heilsoffenbarung betonen und damit einen qualitativen Unterschied zwischen dieser Offenbarung und den Geltungsgrundlagen der außerchristlichen Religionen behaupten. Ich rechne auch die aus der Yaleschool und ihrem Umfeld hervorgegangene "postliberale« - und teilweise die »komparative Theologie« von R. C. Neville, F. X. Clooney, S. J. Duffy, J. L. Fredericks und S. Mark Heim - dazu ${ }^{1}$, die in betonter Bindung an die christliche Tradition vor allem die Differenz zu anderen Traditionen markieren und auf paradigmatische interreligiöse Beziehungsbestimmungen und Deutungen verzichten wollen. Zusammen mit den o.g. Bewegungen, die primär an der Darstellung des spezifisch und unterscheidend Christlichen orientiert sind, kann man sie als "partikularistisch« bezeichnen; denn sie stehen Auffassungen gegenüber, welche die Universalität der göttlichen Offenbarung und des darin vermittelten Heils hervorheben und den nichtchristlichen Religionen in dieser Hinsicht einen positiven Wert beimessen. Zwischen den universalistischen und den partikularistischen Ansätzen ist keine klare Grenze zu ziehen. In der Regel nehmen sie das Anliegen des jeweils anderen in sich auf. Der Unterschied besteht eher in der Akzentsetzung.

Fünf im Jahre 1992 erschienene englischsprachige Beiträge zu einer evangelikalen Religionstheologie sind in einer Sammelrezension in Heft 1/1995 der Zeitschrift »Dialog der Religionen« (67-76) von S. Mark Heim vorgestellt. Im gleichen Jahr erschienen der von Dennis L. Okнolm und TimoThy R. Phillips hg. Sammelband »More than One Way? Four Views on Salvation in a Pluralistic World" und der von EDward Rommen und Harold Netland hg. Band »Christianity and the Religions. A Biblical Theology of World Religions« sowie Alvin Plantingas Aufsatz »Pluralism. A Defense of Religious Exclusivism «. ${ }^{2}$

In einem Exkurs stellt Pius F. Helfenstein in seiner bereits erwähnten Studie »Grundlagen des interreligiösen Dialogs« (s.o. S. 29f.) den von ihm sog. traditionell-evangelikalen Ansatz von Ken R. Gnanakan, den postliberal-evangelikalen Entwurf Lesslie Newbigins und den selbstkritisch-evangeli-

${ }^{1}$ Siehe die Darstellung in Paul F. Knitter, Introducing Theology of Religions, 203215; Klaus von Stosch, Komparative Theologie - ein Ausweg aus dem Grunddilemma jeder Theologie der Religionen? ZKTh 124 (2002) 294-311.

${ }^{2}$ In: Thomas D. Senot $(\mathrm{Hg})$, The Rationality of Belief and the Plurality of Faiths, 1995, 191-215. 
kalen Ansatz von John Sanders und Clark H. Pinnock dar und unterzieht sie einer Wertung (411 ff.).

Pinnock kann als einer der profiliertesten Vertreter einer evangelikal-bekenntnisorientierten Religionstheologie gelten. Er nähert sich dabei allerdings stark einem Inklusivismus an, wie er in »Nostra aetate« begegnet. Von seinem Ansatz beeinflusst und ihm in vielem folgend hat Amos YoNG in »Beyond the Impasse. Toward a Pneumatological Theology of Religions« 2003 eine beachtenswerte Religionstheologie aus charismatischer Perspektive vorgelegt.

Um eine breit angelegte und sachliche Darstellung bemüht sich VELIMatti KärkкÄInen in seiner »Introduction to the Theology of Religions. Biblical, Historical \& Contemporary Perspectives« von 2003. Nach einer Summierung des biblischen Befundes zum Thema und einem Gang durch die Theologiegeschichte präsentiert er einen weiten Überblick über die in der gegenwärtigen Diskussionslandschaft vertretenen Ansätze, sowohl der verschiedenen konfessionellen Traditionen als auch zahlreicher einzelner Theologen. Dabei nehmen die evangelikalen und charismatisch-theologischen Positionen relativ breiten Raum ein, was dem Buch aber gerade in dieser Hinsicht einen spezifischen Informationswert gibt.

Die überarbeitete Version seiner bei George Lindbeck entstandenen Dissertation hat George Sumner unter dem Titel »The First and the Last. The Claim of Jesus Christ and the Claims of Other Religious Traditions« im Jahre 2004 veröffentlicht. Er entfaltet darin das Programm einer postliberalen (von S. »postpluralistisch « genannten) Religionstheologie Lindbeck'scher Prägung, das von den "partikularistischen" (8ff.) Ansätzen Lindbecks, DiNioas, Newbigins, Heims ausgeht, nach dem zentralen Thema bzw. dem identitätsstiftenden Strukturprinzip der christlichen Tradition fragt und dieses in der Behauptung der »final primacy« Jesu Christi entdeckt. Das so ausgewiesene Zentrum der `Grammatikı der christlichen Tradition wird dann in verschiedenen Relationen entfaltet: in Beziehung auf die Ansätze Barths, Rahners, Pannenbergs (64103), im Lichte trinitarisch-heilsgeschichtlicher Konzepte (104-127), hinsichtlich der Missionstheologie (128-151), im Kontext christlicher Reflexionen indischer Prägung (152-175) und im Rahmen von Inkulturationstheologien (176-209). Am Ende steht das Plädoyer für eine disputative Form des Religionsdialogs.

In seinen beiden im Berichtszeitraum erschienenen Büchern »Salvations. Truth and Difference in Religion« (1995) und »The Depth of the Riches: A Trinitarian Theology of Religious Ends« (2000) spricht sich S. Mark Heim gegen die spluralistischer These aus, dass sich in den Erlösungsreligionen letztlich der gleiche soteriologische Grundvorgang vollzieht, so dass die Religionen nur verschiedene Heilswege zum gleichen Ziel darstellen. Demgegenüber plädiert er dafür, die reale Verschiedenheit der religiösen Heilsziele 
ernst zu nehmen, diese aber daraufhin zu prüfen, ob und inwieweit sie in die volle Gemeinschaft mit dem dreieinigen Gott führen. Dabei zeigt sich nach seiner Auffassung, dass die Heilsziele der Religionen lediglich einzelne und begrenzte Dimensionen dieser Gemeinschaft realisieren, wofür sie Anerkennung verdienen, dass aber Erlösung im vollumfänglichen Sinn der personalen Beziehung zum in sich beziehungsreichen Gott lediglich im christlichen Glauben verwirklicht ist. Es handelt sich bei dieser Position um einen Inklusivismus mit eindeutigem Superioritätsanspruch für das in Christus vermittelte Heil.

Für den Bereich der deutschsprachigen Theologie ist vor allem auf die beiden, 1999 von Ralph Pechmann und Martin Reppenhagen hg. Bände "Zeugnis im Dialog der Religionen und der Postmoderne« und »Mission im Widerspruch. Religionstheologische Fragen heute und Mission morgen« zu verweisen, sowie auf: Thomas Schir Rmacher (Hg): Kein anderer Name. Die Einzigartigkeit Jesu Christi und das Gespräch mit nichtchristlichen Religionen (FS P. Beyerhaus), 1999.

Ein etwas genauerer Blick soll auf zwei Bücher Gerhard Gädes geworfen werden, die sich allerdings thematisch eng berühren. In enger Anlehnung an die Arbeiten seines Lehrers Peter Knauer und unter Aufnahme zentraler Einsichten von Karl Rahner und Raimondo Panikkar legt der Verfasser in seiner Habilitationsschrift »Viele Religionen - ein Wort Gottes. Einspruch gegen John Hicks pluralistische Religionstheologie« (1998) einen religionstheologischen Entwurf vor, der sich dezidiert der christlichen Glaubensperspektive verpflichtet weiss. In z.T. scharfer Kritik an der PTR John Hicks, die nach G. die christlichen Glaubensgrundlagen verlassen und sich in die luftige Höhe einer überreligiösen Vogelperspektive verstiegen hat, will er die Religionen vom biblisch überlieferten, trinitätstheologisch entfalteten Verständnis Gottes und seines in Christus verkörperten Wortes aus deuten.

Das für die christliche Botschaft zentrale »Wort Gottes« macht offenbar, dass die "Welt» (d.h. die conditio des adamitischen Menschen einschließlich seiner religiösen Sinnsuche) "von vorneherein hineingeschaffen ist in das Verhältnis des Vaters zum Sohn, welches als der Heilige Geist Gott selber ist « (364). Diesen Grundgedanken legt G. christologisch und pneumatologisch aus (eigentümlicherweise stellt er jedoch keine explizite Beziehung zum schöpferischen Wirken der ersten trinitarischen Person her).

Christologisch geht er aus von der Unterscheidung zwischen dem Logos (bzw. Wort) Gottes und der von diesem angenommenen geschöpflichen und daher geschichtlich begrenzten Wirklichkeit des Menschseins Jesu. So sehr die Fülle Gottes in Jesus wohnt, so sehr übersteigt die unendliche göttliche Wirklichkeit des Logos doch dessen menschliche Existenz. Indem sich diese Fülle in Jesus verkörpert, begrenzt sie sich nicht, sondern offenbart ihre Unendlichkeit durch ein endliches, historisches Medium. Sie offenbart, dass die gesamte Menschheitsgeschichte im Logos Christus geschaffen und damit in das Gegenüber des Sohnes zum Vater gestellt ist. Der inkar- 
nierte Logos wird auf diese Weise zum »hermeneutischen Schlüssel«, um das eigentliche Wesen der Welt, der menschlichen Religiosität und auch der Religionen coram Deo zu verstehen. Durch diesen hermeneutischen Schlüssel erschließen sich die Religionen nun als Heilswege, die auf den universalen Heilswillen Gottes antworten (341 ff.). Doch tun sie das nicht schon in ihrem angestammten Selbstverständnis, sondern erst indem sie den in ihnen verborgenen Christus in einer Weise zur Sprache bringen, die sie selbst nicht wirklich verstehen. Es ist dieselbe unüberbietbare Christus-Gnade, die im Christentum wie in den Religionen wirkt - mit dem Unterschied, dass sie hier offenbar wurde und dort verborgen bleibt (343). Dieser Gedanke führt unmittelbar hinüber in die pneumatologischen Überlegungen.

Als »Hermeneut des Wortes« ist der Heilige Geist nach G. die Möglichkeitsbedingung für den Empfang und das Verständnis des Kerygmas (338ff.). Er geht ihm voraus und macht die Menschen aufnahmebereit. Wenn ihnen das eine Wort Gottes, in dem er sich selbst mitteilt, dann verkündet wird, schließt er es ihnen auf und inspiriert sie, es zu verstehen und anzunehmen. »Der Logos kann nur dort ankommen, wo das Pneuma bereits da ist « (339; vgl. 311). Auf diese Weise bewirkt der Geist auch das rechte Verständnis der in den Religionen verborgenen Christusgegenwart. Indem er sie aufdeckt und in ihrem eigentlichen Wesen bekannt macht, überführt er den impliziten Glauben, der auch in den nichtchristlichen Religionen vorhanden ist, in den expliziten Christusglauben. Mit dieser Auffassung schließt G. unmittelbar an Karl Rahners Lehre vom »anonymen« Christsein an. Dabei betont er, dass die Beziehung zwischen anonymem und explizitem Glauben nicht als Überbietung nach dem Schema von Teil und Fülle zu deuten ist, sondern als 'Entbergung` dessen, was der implizite Glauben seinem eigentlichen Wesen nach ist (340).

Der Hl. Geist wirkt universal. Daher kann G. konstatieren, dass »auch die Anhänger anderer Religionen bereits von diesem Geist erfüllt sind « (340) und dass er - für Christen in seiner Eigentlichkeit verstehbar - auch aus diesen Religionen spricht (341). Interreligiöser Dialog ereignet sich darum als pfingstliche Kommunikation.

Die universale Präsenz des Geistes in der geschaffenen Wirklichkeit geht aus von seiner innertrinitarischen Wirklichkeit als Beziehungsgeschehen zwischen Gott-Vater und dem Sohn. Im (expliziten wie impliziten!) Glauben ist der Mensch einbezogen in dieses innergöttliche Gegenüber. Der gleiche Geist, der die communio zwischen der ersten und der zweiten Person der Trinität erfüllt, stiftet Gemeinschaft der Menschen mit Gott (die zum expliziten Glauben hinstrebt) und Gemeinschaft der Menschen untereinander (347).

G.s Konzept einer johanneisch eingefärbten Logostheologie stellt die Christusbotschaft (d.h. die Selbstmitteilung Gottes, die nicht mit dem Christentum als historischer Religion identifiziert werden darf, 354) den Religionen (als Manifestationen menschlicher Heilssehnsucht) gegenüber. Darin erinnert es an das Offenbarungs- und Religionsverständnis der Wort-GottesTheologie Karl Barths. Das Christuskerygma ist nach G. der Schlüssel, der die in den Religionen unkenntliche Christusgegenwart erschließt. Die Religionen können von daher als sich selbst missverstehende Heilswege gewürdigt werden, die der Erleuchtung durch den Hl. Geist bedürfen. In Wirklich- 
keit stehen sie schon in der geistlichen Gemeinschaft des göttlichen Vaters mit seinem Sohn, doch sind sie sich dessen nicht bewusst.

Die Auslegung der christlichen Trinitätslehre auf die Religionen bedient sich hier eines theologischen Religionsbegriffs (293ff.), der ihre realen Artikulationen ebenso ignoriert wie ihre jeweiligen Selbstverständnisse. Nicht einmal ansatzweise wird der Versuch unternommen, die Selbstvollzüge der Religionen und die sich darin zum Ausdruck bringenden Anliegen authentisch zu verstehen, um dann das interreligiöse Begegnungsgeschehen theologisch zu reflektieren.

Dass die Christusbotschaft selbst ein Teil der zutiefst menschlichen Religionsgeschichte ist, wird programmatisch ausgeblendet, um sie (oder eher: den eigenen religiösen Auslegungshorizont) in einer ideologiekritisch leicht durchschaubaren Immunisierungsstrategie und in z.T. deduktiv-zirkulären Argumentationen zum überreligiös archimedischen Punkt zu erklären, von dem aus sich die Wahrheit aller Religionen enthüllen soll. Wenn diese auch als Heilswege gewürdigt werden, so doch nur unter der Bedingung, dass es sich bei dem Heil in ihnen um das anonyme, d.h. ihnen selbst verborgene Christusheil handelt, was wiederum nur durch den expliziten Christusglauben eingesehen werden kann.

So sehr G.s Diskussionsbeitrag auch beansprucht, den religionstheologischen Inklusivismus hinter sich zu lassen, so offensichtlich bleibt er in der Sache doch der inklusivistischen Vorstellung vom »anonymen Christentum« (Rahner) und vom »unbekannten Christus in den Religionen « (beim frühen Panikkar) verhaftet. Und so sehr er den Anspruch erhebt, sich von der vermeintlichen Standpunktlosigkeit des religionstheologischen Pluralismus abzugrenzen, so deutlich strebt er doch selbst nach einer überreligiösen, die Partikularität der eigenen Glaubensperspektive hinter sich lassenden Universalschau. Die wiederholt vorgetragene Beteuerung der Perspektivität dieses Ansatzes (312f.) wird nicht in seine inhaltliche Entfaltung integriert. Und daher ist die von Knauer inspirierte und von G. propagierte randere Absolutheit des Christusglaubens im Kern nicht so sehr anders als die von der Wort-Gottes-Theologie Barth'scher Prägung oder die von der Transzendentaltheologie Rahner'scher Prägung behauptete.

Gerhard Gädes 2003 erschienenes Buch »Christus in den Religionen. Der christliche Glaube und die Wahrheit der Religionen« präsentiert die gleiche Position in einer weniger wissenschaftlich-theologischen Form für ein breiteres Zielpublikum.

Nach einer Einführung, in der die Aufgabenstellung und die Probleme der Theologie der Religionen umrissen werden, grenzt sich G. im ersten Kapitel von Relativismus und Fundamentalismus als zwei Irrwegen ab; er kritisiert im zweiten Kapitel auch die drei religionstheologischen Modelle des Exklusivismus, Inklusivismus und Pluralismus als Sackgassen, um damit den Boden für die Suche nach einer Alternative zu bereiten. Diese glaubt er in dem von ihm sog. Modell des religionstheologischen »Interioris- 
mus« zu finden, das Christus nicht gegen, über oder neben die Religionen stellt (wie es seiner Auffassung nach im Exklusivismus, Inklusivismus und Pluralismus geschieht), sondern in ihnen aufsucht - als verborgenes Zentrum des von ihnen verkündeten Heils. Diese Position, die er im dritten Kapitel durch eine Reflexion auf die Ambivalenz der Religion vorbereitet, entwickelt er im vierten Kapitel aus der Beziehungsbestimmung zwischen Altem und Neuem Testament. Im Anschluss an Peter Knauer formuliert er die folgende These: »In dem kanonischen Verhältnis des Neuen Testaments zum Alten in der einen christlichen Bibel ist das Paradigma präformiert, um aus der christlichen Glaubensperspektive auch andere Religionen in den Blick zu nehmen und deren unüberbietbare Wahrheit zu erkennen und universal verkündbar zu machen« (161). Diese von ihnen selbst nicht verstandene Wahrheit liege in Christus, dem Licht zur Erleuchtung der Heiden (171) und werde von der (römisch-katholischen) Kirche verkündet. Der vermeintliche Königsweg des Interiorismus ist nichts anderes eine neue Mixtur von Exklusivismus und Inklusivismus.

Auch die von Gerhard Ludwig Müller und Massimo Serretti hg. Aufsatzsammlung »Einzigkeit und Universalität Jesu Christi im Dialog mit den Religionen« (2001) befasst sich mit dem Verständnis Jesu Christi angesichts der Herausforderung, die vor allem durch die Ansätze der PTR gestellt wurde. Demgegenüber bekräftigen die Autoren ganz im Geiste von »Dominus Iesus« die Einzigkeit und Universalität der Heilsmittlerschaft Christi, was schon in der Übereinstimmung zwischen dem Titel des Bandes und dem Untertitel von »Dominus Iesus« zum Ausdruck kommt.

Bei den von M. und S. zusammengestellten Texten handelt es sich mit einer Ausnahme nicht um Erstveröffentlichungen, sondern um bereits publizierte Artikel, denen eine gegenüber der PTR kritische, teilweise polemische Tendenz und die Treue zu lehramtlichen Äußerungen gemeinsam ist. In einigen Beiträgen (etwa bei M. selber) wird dabei auf die Texte der angegriffenen religionstheologischen Entwürfe kaum oder gar nicht im Wortlaut und unter Hinweis auf die genaue Belegstelle Bezug genommen. Vielmehr rekonstruieren die Verfasser deren Position - wiederum ganz im Stil der Dekretionsrhetorik von »Dominus Iesus« - in anonymer, der Überprüfbarkeit entzogener, damit aber auch ihres Anspruchs auf Wissenschaftlichkeit entledigter Allgemeinheit.

Die von M. ausgewiesenen »Aporien der postchristlichen Pluralistischen Religionstheologie» (32ff.) lassen sich denn auch nur als tendenziöse Verzeichnungen der Intention von Hick, Knitter, Schmidt-Leukel u.a. beurteilen. Noch weiter in der Polemik geht S. Nach seiner Analyse besteht »das Vorhaben von Hick und Knitter darin, eine urtümliche Theologie zu formulieren, die von der Metaphysik und der Offenbarung, von der Anthropologie und der Schöpfung absieht« (74). Demgegenüber führt er einen neoscholastischen Transzendentalienrealismus ins Feld.

Angelo Scola und Marcello Bordoni entfalten ihre religionstheologischen Überlegungen weitgehend aus der Rezeption lehramtlicher Verlautbarungen. Scolas einleiten- 
der Artikel besteht in einer Auslegung des nachsynodalen Apostolischen Schreibens "Ecclesia in Asia«, Bordoni stellt das von ihm sog. metaphysische Wirklichkeitsverständnis im Rahmen einer eher kontemplativen als argumentativen Theologie dar. Michael Schulz stützt sich in seiner Auseinandersetzung mit der PTR auf einen einzigen Artikel von Perry Schmidt-Leukel. Dessen Plädoyer für eine offenbarungstheologische und soteriologische Wertschätzung der traditionsreichen nichtchristlichen Religionen hält er die Auffassung entgegen, in diesen Religionen drücke sich lediglich »die Suche des Menschen nach Gott aus sowie eine vorläufige Wahrnehmung und Anerkenntnis der göttlichen Macht« (147; ähnlich Müller, 43). Ein ekklesiozentrischer Inklusivismus ist hier mit einem christologischen Exklusivismus verbunden. Wie sehr auch bei ihm der Wissenschaftscharakter der Theologie zur Disposition gestellt wird, zeigt sich in seiner unmittelbaren Übertragung des unbedingten Verpflichtungsanspruchs, wie er dem Glauben eigen ist, auf die theologische Reflexion. - Deutlich über Schulz hinaus geht Bruno Forte, wenn er die Religionen nicht nur als »Ausdruck der Selbsttranszendenz des Menschen im Hinblick auf das heilige Geheimnis, sondern auch als Ort der göttlichen Selbstmitteilung« (276) ansieht. In Aufnahme der Texte des Zweiten Vatikanischen Konzils und der Enzyklika »Redemptoris Missio hält er an einem offenen Inklusivismus fest. - Horst Bürkle verwahrt sich in seinem Beitrag gegen eine Unterbestimmung der Differenzen zwischen der in Christus geoffenbarten Wahrheit und den asiatischen Religionen, besonders dem Buddhismus, weil dadurch die Einzigartigkeit und Einmaligkeit des Christusereignisses im Sinne des asiatischen Religionsverständnisses relativiert werden würde.

In ähnlicher Weise begegnet das Bekenntnis zur Einzigkeit der Christusoffenbarung und des kirchlichen Heilsweges auch in anderen Beiträgen als vorausgesetztes Postulat, aus dem dann Ableitungen vorgenommen werden (und nicht umgekehrt als Zielpunkt der Argumentation, der etwa durch religionsvergleichende Betrachtungen zu erreichen wäre). So argumentiert Walter Kasper, das für die Pluralistischen Religionstheologien charakteristische humanistische Wahrheitskriterium sei nicht ausreichend, weil man mit ihm nicht »die Einzigartigkeit einer bestimmten, konkret: der christlichen Religion« (163) erweisen könne. In hermeneutischer Zirkularität entfaltet auch Karl-Heinz Menke die Voraus-Setzung von der einmaligen Selbstoffenbarung Gottes in Christus - besonders in seinem Kreuzestod. Er wirft den Vertretern der PTR eine mangelnde Unterscheidung zwischen Wort und Geist und damit eine Verkürzung der Trinitätslehre vor und stellt dem - besonders im Dialog mit von Balthasar und Verweyen - eine Entfaltung der Implikationen des Inkarnationsgeschehens, d.h. der Selbstvergegenwärtigung des Absoluten im Endlichen gegenüber.

Zwei Werke von Autoren, die mit ihren Beiträgen in diesem Band vertreten sind, seien nur kurz angezeigt: 1995 ist Karl-Heinz Menkes Buch »Die Einzigkeit Christi im Horizont der Sinnfrage« erschienen und ein Jahr später von HorsT BürKLE »Der Mensch auf der Suche nach Gott - die Frage der Religionen«.

\section{Religionssperifsche Religionstheologien}

Hans-Martin Barth (Hg.), Buddhismus und Christentum. Jodo Shinshu und evangelische Theologie (III. Internationales Rudolf-Otto-Symposion). EB, Hamburg 2000, 219 S. - Hans-Martin Barth (Hg.), Hermeneutik in Islam und Christentum. Beiträge zum Interreligiösen Dialog (Rudolf-Otto-Symposion 1996). EB, Hamburg 1997, 
202 S. - Martin Bauschke, Jesus im Koran, Böhlau. Köln u.a. 2001, XII + 210 S. Andreas Bsteh (Hg.), Beiträge zur Religionstheologie. Bd. 2: Der Gott des Christentums und des Islams, 1978, 192 S.; Bd. 3: Erlösung in Christentum und Buddhismus, 1982, 200 S.; Bd. 4: Sein als Offenbarung in Christentum und Hinduismus, 1984, 236 S.; Bd. 5: Dialog aus der Mitte christlicher Theologie, 1987, 245 S.; Bd. 7: Hören auf sein Wort. Der Mensch als Hörer des Wortes Gottes in christlicher und islamischer Überlieferung, 1992, 220 S.; Bd. 8: Friede für die Menschheit. Grundlagen, Probleme und Zukunftsperspektiven aus islamischer und christlicher Sicht. Internationale Christlich-Islamische Konferenz, Wien, 30. März bis 2. April 1993, 1994; Bd. 9: Eine Welt für alle. Grundlagen eines gesellschaftspolitischen und kulturellen Pluralismus in christlicher und islamischer Perspektive. Zweite Internationale Christlich-Islamische Konferenz Wien 1997, 1999, 431 S.; alle Bände St. Gabriel, Mödling - Andreas Bsten (Hg.), Studien zur Religionstheologie, hg. vom Religionstheologischen Institut der Theologischen Hochschule St. Gabriel. SzR 1: Der Islam als Anfrage an christliche Theologie und Philosophie, 1994, 545 S.; SzR 2: Christlicher Glaube in der Begegnung mit dem Islam, 1996, 616 S.; SzR 3: Der Hinduismus als Anfrage an christliche Theologie und Philosophie, 1997; SzR 4: Christlicher Glaube in der Begegnung mit dem Hinduismus, 1998, 672 S.; SzR 5: Der Buddhismus als Anfrage an christliche Theologie und Philosophie, 2000, 590 S.; SzR 6: Christlicher Glaube in der Begegnung mit dem Buddhismus, 2001, 606 S.; alle Bände St. Gabriel, Mödling - Katharina Ceming, Einheit im Nichts. Die mystische Theologie des Christentums, des Hinduismus und Buddhismus im Vergleich. Edition Verstehen, Augsburg 2004, 387 S. Ulrich Dehn, Den Buddhismus verstehen. Versuche eines Christen. Lembeck, Frankfurt 2004, 210 S. - Sybille Fritsch-Oppermann, Christliche Existenz im buddhistischen Kontext. Katsumi Takizawas und Seiichi Yagis Dialog mit dem Buddhismus in Japan (Beiträge zur Missionswissenschaft und interkulturellen Theologie 12). LIT-Verlag, Münster u.a. 2000, IX + 329 S. - Ludger Kaulig, Ebenen des christlich-islamischen Dialogs. Beobachtungen und Analysen zu den Wegen einer Begegnung. LIT-Verlag, Münster 2004, 440 S. - Hans KüNG, Der Islam. Geschichte Gegenwart - Zukunft. Die religiöse Situation der Zeit. Piper, München / Zürich 2004, 891 S. - Karl-Josef Kuschel, Streit um Abraham. Was Juden, Christen und Muslime trennt - und was sie eint. Piper, München 1994, 334 S. - Reinhard Leuze, Christentum und Islam. Mohr, Tübingen 1994, VII + 317 S. - Armin Münch, Dimensionen der Leere. Gott als Nichts und Nichts als Gott im christlich-buddhistischen Dialog (Studien zur systematischen Theologie und Ethik 16). LIT-Verlag, Münster 1998, 337 S. - Hans J. Münk und Michael Durst (Hgg.), Christliche Theologie und Weltreligionen. Grundlagen, Chancen und Schwierigkeiten des Dialogs heute (Theologische Berichte 26). Paulusverlag, Freiburg (CH) 2003, 239 S. - Horst Georg PöHLMANN, Begegnungen mit dem Buddhismus. Dialoge, Erfahrungen und Grundsatzüberlegungen. Ein Beitrag zum interreligiösen Gespräch. Lembeck, Frankfurt 1998, 181 S. - Horst Georg Pöhlmann, Begegnungen mit dem Hinduismus. Dialoge, Beobachtungen, Umfragen und Grundsatzüberlegungen nach zwei Indienaufenthalten. Ein Beitrag zum interreligiösen Gespräch. Lembeck, Frankfurt 1995, 205 S. - SiEGFried RaEder, Der Islam und das Christentum. Eine historische und theologische Einführung. Neukirchener Verlag, Neukirchen-Vluyn 2001, XVIII + 284 S. - Andreas Renz, Der Mensch unter dem An-Spruch Gottes. Offenbarungsverständnis und Menschenbild des Islam im Urteil gegenwärtiger christlicher Theologie. Ergon, Würzburg 2002, VI + 608 S. - André Ritter, Der Monotheismus als ökumenisches Problem. Eine Studie zum trinitarischen Denken und Reden von Gott im Kontext des christ- 
lich-muslimischen Dialogs. EB, Hamburg 1998, 365 S. - Arnulf von Scheliha, Der Islam im Kontext der christlichen Religion (Studien zum interreligiösen Dialog 6). Waxmann, Münster u.a. 2004, 188 S. - Hansjörg Schmid / Andreas Renz / Jutta Sperber (Hg.), Heil in Christentum und Islam. Erlösung oder Rechtleitung? (Hohenheimer Protokolle 61). Akademie der Diözese Rottenburg-Stuttgart, Stuttgart 2004, 256 S. - Hansjörg Schmid / Andreas Renz / Jutta Sperber (Hg.), Herausforderung Islam (Hohenheimer Protokolle 60). Akademie der Diözese Rottenburg-Stuttgart, Stuttgart 2003, 176 S. - Hansjörg Schmid / Andreas Renz / Jutta Sperber (Hgg.), »Im Namen Gottes ...« Theologie und Praxis des Gebets in Christentum und Islam. Friedrich Pustet, Regensburg 2006, 246 S. - Venanz Schubert, Religionen im Aufbruch. Identität - Konflikt - Toleranz (Wissenschaft und Philosophie 18). EOS, St. Ottilien 1999, 325 S. - Hans Waldenfels (Hg.), Der Islam. Religion und Politik (Politik- und kommunikationswissenschaftliche Veröffentlichungen der Görres-Gesellschaft 23). Schöningh, Paderborn 2004, 116 S.

Während die bisher angezeigten und besprochenen Schriften zumeist Fragen der religionsphilosophischen und theologischen Grundlegung der Religionstheologie behandeln und darin eher programmatischen Charakter haben, wenden sich die smaterial-religionsdialogischen Arbeiten bestimmten theologischen Themen zu, die sich aus der Begegnung des Christentums mit andern Religionen ergeben. Sie gehen von interreligiösen Diskursen aus und reflektieren die dort auftretenden Gemeinsamkeiten und Unterschiede in Lehre und Praxis. Wiederum ohne Anspruch auf Vollständigkeit beschränke ich mich auf die - exemplarische - Nennung der Titel von Monographien und Sammelbänden zur theologischen Auseinandersetzung mit dem Islam, sowie mit Hinduismus und Buddhismus aus den letzten zehn Jahren. Eine zweibändige Aufsatzsammlung aus der Reihe »Studien zur Theologie der Religionen« (SzR) greife ich heraus und wende mich ihr eingehender zu.

Zum theologischen Dialog mit dem Islam ist hinzuweisen auf die von Andreas Bsteh hg. Bände »Der Islam als Anfrage an christliche Theologie und Philosophie« (1994) und »Christlicher Glaube in der Begegnung mit dem Islam« (1996). - In der ebenfalls von Andreas Bsteh hg. Reihe »Beiträge zur Religionstheologie« sind erschienen: Bd.2: Der Gott des Christentums und des Islams (1978, 1992²), Bd.7: Hören auf sein Wort. Der Mensch als Hörer des Wortes Gottes in christlicher und islamischer Überlieferung (1992), Bd.8: Friede für die Menschheit. Grundlagen, Probleme und Zukunftsperspektiven aus islamischer und christlicher Sicht (1994), Bd.9: Eine Welt für alle. Grundlagen eines gesellschaftspolitischen und kulturellen Pluralismus in christlicher und islamischer Perspektive (1999), wobei die beiden zuletzt genannten Bände die 1. und die 2. Internationale Christlich-Islamische Konferenz Wien in den Jahren 1993 und 1997 dokumentieren. - Die Publikationen der bisher drei »Iranisch-Österreichischen Konferenzen« und 
des »Vienna International Christian-Islamic Round Table« enthalten ebenfalls beachtenswerte Beiträge.

Seit 2003 veranstaltet die Akademie der Diözese Rottenburg-Stuttgart jährlich Tagungen des »Theologischen Forums Christentum - Islam«, deren Beiträge von Hansjörg Schmid, Andreas Renz und Jutta Sperber zunächst als Hohenheimer Protokolle herausgegeben wurden: Herausforderung Islam (Bd. 60); Heil in Christentum und Islam. Erlösung oder Rechtleitung? (Bd. 61). Die Tagung des Jahres 2005 ist dokumentiert in dem Band »Im Namen Gottes ... Theologie und Praxis des Gebets in Christentum und Islam

Ausgewählte Monographien zur theologischen Beschäftigung mit dem Islam: Reinhard Leuze, Christentum und Islam (1994); Karl-Josef Kuschel, Streit um Abraham. Was Juden, Moslems und Christen trennt - und was sie eint (1994); HansMartin Barth (Hg.), Hermeneutik in Islam und Christentum (1997); André Ritter, Der Monotheismus als ökumenisches Problem. Eine Studie zum trinitarischen Denken und Reden von Gott im Kontext des christlich-muslimischen Dialogs (1998); Siegfried Raeder, Der Islam und das Christentum. Eine historische und theologische Einführung (2001, 201-277); Andreas Renz, Der Mensch unter dem An-Spruch Gottes. Offenbarungsverständnis und Menschenbild des Islam im Urteil gegenwärtiger christlicher Theologie (2002); Martin Bauschke, Jesus im Koran (2001); Hans KüNG, Der Islam. Geschichte - Gegenwart - Zukunft. Die religiöse Situation der Zeit (2004); Ludger Kaulig, Ebenen des christlich-islamischen Dialogs. Beobachtungen und Analysen zu den Wegen einer Begegnung (2004); Arnulf von Schelina, Der Islam im Kontext der christlichen Religion (2004). Der 2004 erschienene, von Hans Waldenfels hg. Tagungsband »Der Islam: Religion und Politik« enthält interessante, aber nicht primär auf eine theologische Auseinandersetzung zielende Aufsätze von H. Waldenfels, H. Maier, R. Wieland, H. Bürkle, A.Th. Khoury, W. Kluxen, H. Bielefeldt und Th. Lemmen. Darüber hinaus ist zu verweisen auf die z.T. schon älteren Arbeiten von Hans Zirker und Ludwig Hagemann.

Zur theologischen Auseinandersetzung mit dem Hinduismus ist zunächst wiederum auf die von Andreas Bsten hg. Bände »Der Hinduismus als Anfrage an Christliche Theologie und Philosophie« (1997) sowie »Christlicher Glaube in der Begegnung mit dem Hinduismus« (1998) hinzuweisen. Zudem ist vom gleichen Herausgeber in der Reihe »Beiträge zur Religionstheologie» als Bd. 4 erschienen: "Sein als Offenbarung in Christentum und Hinduismus« $\left(1984,1992^{2}\right)$.

Auf die Bedeutung Raimondo Panikkars für den christlich-hinduistischen Dialog wurde schon hingewiesen. Seine persönliche spannende Entdeckungsreise in den Hinduismus hat Horst Georg Pöhlmann dokumentiert in dem Band: »Begegnungen mit dem Hinduismus: Dialoge, Beobachtungen, Umfragen und Grundsatzüberlegungen nach zwei Indienaufenthal- 
ten. Ein Beitrag zum interreligiösen Gespräch«. 2004 erschien Katharina Cemings Habilitationsschrift »Einheit im Nichts. Die mystische Theologie des Christentums, des Hinduismus und Buddhismus im Vergleich«.

Ungleich größer ist die Zahl der Beiträge zur theologischen Auseinandersetzung mit dem Buddhismus, wobei die Arbeiten von Hans Waldenfels und Michael von Brück in Zeiten einfacher Internetrecherchen nicht einzeln aufgeführt werden müssen. Perry Schmidt-Leukels Beiträge wurden schon genannt. Horst Georg Pöhlmann hat seinem Band zum Dialog mit dem Hinduismus einen ebensolchen zum Buddhismus zur Seite gestellt (1998). Ebenfalls 1998 kam Armin MüNchs Dissertation unter dem Titel »Dimensionen der Leere: Gott als Nichts und Nichts als Gott im christlich-buddhistischen Dialog« auf den Markt. Im »European Network of Buddhist Christian Studies« hat sich die Begegnung mit dem Buddhismus eine Plattform gegeben (www.buddhist-christian-studies.org), auf der regelmäßig Tagungen statt finden. Die Beiträge zum III. Internationalen Rudolf-Otto-Symposion am Fachbereich Evangelische Theologie der Philipps-Universität Marburg in Zusammenarbeit mit der Otani-Universität, Kyoto 1999 wurden 2000 unter dem Titel »Buddhismus und Christentum. Jodo Shinshu und evangelische Theologie« veröffentlicht. Im gleichen Jahr erschien die Dissertation von Sybille Fritsch-Oppermann: „Christliche Existenz im buddhistischen Kontext. Katsumi Takizawas und Seiichi Yagis Dialog mit dem Buddhismus in Japan«. 2004 hat Ulrich Dehn sein Buch »Buddhismus verstehen. Versuche eines Christen« veröffentlicht.

Einer genaueren Betrachtung sollen die beiden von Andreas Bsteh hg. Bände zur christlichen Begegnung mit dem Buddhismus (Der Buddhismus als Anfrage an christliche Theologie und Philosophie, 2000; Christlicher Glaube in der Begegnung mit dem Buddhismus, 2001) unterzogen werden. Sie stehen in der sechsbändigen Reihe religionstheologischer Studien, die vom Religionstheologischen Institut der Theologischen Hochschule St. Gabriel in Mödling bei Wien seit 1994 publiziert wurde. Diese Reihe besteht aus drei mal zwei Bänden, die der theologischen Auseinandersetzung mit dem Islam, dem Hinduismus und dem Buddhismus gewidmet sind. Der jeweils erste der Doppelbände soll die Herausforderung darstellen, die von der dort in den Blick genommenen Religion für die christliche Theologie ausgeht, während der zweite Band diese Anfragen aufnimmt und theologisch (»im Geiste christlichen Glaubens und tiefer Ehrfurcht vor der Andersheit der nichtchristlichen Religionen«, SzR 1, 8) zu reflektieren versucht. Alle sechs Bände sind aus den »Religionstheologischen Akademien« in St. Gabriel hervorgegangen und dokumentieren auch die Gespräche, die sich an die Vorträge angeschlossen haben. Anders als die z.T. aus den vier »Religions- 
theologischen Studientagungen« erwachsenen »Beiträge zur Religionstheologie« sind die »Studien« nicht religionsdialogisch angelegt, d.h. es kommen keine Dialogpartner aus den außerchristlichen Religionen zu Wort. Die Debatte findet zwischen Theologen und Religionswissenschaftlern - Islamkundlern, Indologen, Buddhismusforschern - statt. Sie hat das Ziel, »christliche Theologie in den Fragestellungen der anderen Religionen zu entwickeln« (SzR 1, 6) und dabei auch Exegeten, Dogmatiker, Dogmengeschichtler und Vertreter anderer theologischer Disziplinen mit einzubeziehen. Aus der Mitte der christlichen Theologie, auf dem Fundament des Glaubens, soll die Begegnung mit den Lehr- und Lebensformen der Religionen vollzogen werden. Vielleicht als Reaktion auf die immer wieder geäußerte Befürchtung, in der dialogischen Öffnung für die Religionen könne die Identität des Christlichen verwässert werden, bildet das Proprium des Christlichen hier den Ausgangspunkt. Die Begegnung soll auf dem »Urgestein des Glaubens« aufruhen (SzR 1, 7).

Die beiden Bände zur Begegnung mit dem Buddhismus knüpfen an eine Dialogtagung aus dem Jahr 1981 an, an der führende buddhistische und christliche Gelehrte das Gespräch miteinander aufgenommen hatten. ${ }^{3}$ Den im Bezug auf diese Tagung offensichtlich aufkeimenden Ängsten, solche Dialoge könnten zu einer Nivellierung der charakteristischen Unterschiede zwischen den Religionen führen, wurde mit einer Kurskorrektur entsprochen: Die Zukunft des Dialogs sei »im Austrag der Differenzen zu sehen, die bis in die Wurzeln der entscheidenden Fragen nach dem Sinn des menschlichen Daseins reichen, und dabei [sei] vom Menschen auszugehen, zu dessen Wesen es gehört, in der Erfahrung des unerfüllten Zustandes seiner Existenz nach der Erfüllung auszulangen« (SzR 5, 5). Nach einer Begegnungstagung mit Aloysisus Pieris aus Sri Lanka, der forderte, ein authentischer interreligiöser Dialog müsse »aus der Mitte beider Traditionen « ${ }^{4}$ kommen, wurden die »Religionstheologischen Akademien« ins Leben gerufen, die diesem Programm folgen sollten. 1997 und 1998 fanden die beiden Tagungen zur Begegnung des Christentums mit dem Buddhismus in St. Gabriel statt. Auch sie waren als "geistige Wegstation christlichen Glaubens konzipiert, der um die reichen Schätze religiöser Erfahrung und Einsicht in anderen Religionen weiß und aus seiner eigenen geistigen Identität heraus

\footnotetext{
${ }^{3}$ Publiziert in: Andreas Bsteh (Hg): Erlösung in Christentum und Buddhismus (Beiträge zur Religionstheologie 3), ${ }^{2} 1992$.

${ }_{4}$ Aloysius Pieris, Christentum und Buddhismus im Dialog aus der Mitte ihrer Traditionen, in: Andreas Bsteh (Hg.), Dialog aus der Mitte christlicher Theologie (Beiträge zur Religionstheologie 5) 1987, 131-178.
} 
die Begegnung sucht und den Austausch« (SzR 5, 8). Die Begegnung war als identitätszentrierter Dialog angelegt.

In der ersten der beiden Zusammenkünfte hatten die (an europäischen Universitäten lehrenden) Buddhismusforscher das Wort: In einem ersten Schritt arbeiteten Tilmann Vetter, Lambert Schmithausen und Johannes Bronkhorst die historischen Ursprünge des Buddhismus auf, um so seine spezifische Eigenart historisch-genetisch zu bestimmen und sie von den hinduistischen und jainistischen Traditionen abzugrenzen. Die Gestalt und Lehre des Buddha und mit ihr die Frage nach dem Proprium der buddhistischen Spiritualität im Spannungsfeld von Mitgefühl und Gleichmut stand dabei im Mittelpunkt der Untersuchung des älteren (Theravada-)Buddhismus. Nach Schmithausen bleibt die Spannung zwischen dem Sich-Berührenlassen vom Leid anderer Lebewesen und dem Streben nach der Überwindung des Sich-Berührenlassens, zwischen Engagement und dem Sehnen nach vollkommener innerer Ruhe im älteren Buddhismus letztlich unaufgelöst, wenn sie auch ein deutliches Gefälle zum zweiten der beiden Pole hin hat. Das bedeutet aber nicht, dass Mitgefühl und Fürsorge lediglich zu übersteigende Vorstufen auf dem Erlösungsweg seien. Sie begleiten den Übenden auf allen Stufen des Pfades und treten auch im Zustand der Erleuchtung hervor. In diesem Kontext sind die beeindruckenden Liebesgebote zu lesen, so etwa wenn es im Sutta-nipāta, der »kleinen Sammlung von Lehrvorträgen«, 149 heißt: »Wie eine Mutter ihr eigenes Kind, ihren einzigen Sohn selbst mit ihrem Leben beschützt, also hege der Jünger Buddhas grenzenlose Liebe zu allen Wesen«. Diese Liebe reicht bis zur Feindesliebe.

Die beiden Vorträge von Ernst Steinkellner und die sich daran anschließenden Gespräche im zweiten Teil des Bandes kreisen um den Religionsbegriff und die Anthropologie und damit um zwei Themen, die weniger im Erkenntnisinteresse der Buddhismuskunde selbst liegen, sondern sich eher in den christlich-buddhistischen Begegnungen gestellt haben: Ist der Buddhismus überhaupt als Religion zu charakterisieren (oder eher als Philosophie), wo er doch die Vorstellung eines personalen Gottes dezidiert zurückweist? Steinkellner arbeitet heraus, dass es im Blick auf die Buddhaschaft sinnvoll sein könnte, von einer Transzendenz in der Lehre und der Praxis des Buddhismus zu sprechen, dass dieser Begriff aber mit Konnotationen aufgeladen ist, die an die theistische Religiosität gebunden sind und die daher eine solche Anwendung problematisch erscheinen lassen. Gleiches ist für den Religionsbegriff zu sagen. Für die Sicht des Menschen in Hinduismus und Buddhismus ist zum einen die Kontinuität zwischen allen Lebewesen in ihrer Einbindung in den Kreislauf der Wiedergeburten charakteristisch, zum anderen aber die Vorzugsstellung des Menschen im Blick auf die Erlösung aus diesem Kreislauf.

Der dritte Teil der Tagung und des Tagungsbandes war den beiden Weiterentwicklungen des Theravadabuddhismus hin zum Mahayana (Vetter, Schmithausen) und zu den tantrischen Ausprägungen des Buddhismus (Max Nihom) gewidmet. Interessant ist dabei Schmithausens Rekonstruktion der für die Spiritualität des Mahayana-Buddhismus zentralen Polarität von Mitleid und Leerheit. Gegenüber dem älteren Buddhismus ist das (im Bodhisattvaideal verkörperte) Mitleidsmotiv stärker akzentuiert. Das Heilsziel der Buddhaschaft soll nicht nur für sich angestrebt, sondern auch anderen Menschen zugänglich gemacht werden. Allerdings darf auch das Mitleid keine Anhaftung erzeugen, sondern muss - den Übenden selbst und die von ihm dazu Angelei- 
teten - zum Leerwerden führen. Mitleid und Leerheit relativieren sich also gegenseitig und sind darin wie Gegengewichte aufeinander angewiesen.

Während in den Vorträgen die dargestellten Erscheinungsformen des Buddhismus kaum in Beziehung zu christlichen Lehrinhalten und geschichtlichen Realisationen gesetzt werden, versuchen die christlichen Theologen in den anschließenden Gesprächen Brückenschläge. Über den Austausch von Gelehrsamkeit hinaus kommt es dabei allerdings nicht zu wirklichen gegenseitigen Herausforderungen. Der anvisierte Dialog von Mitte zu Mitte findet nicht statt, weil lediglich eine der beiden im Gespräch befindlichen Religionen durch Vertreter der Innenperspektive repräsentiert ist, die andere aber durch Stellvertreter, die eine westliche religionswissenschaftliche Außenperspektive einnehmen. Christlichen Theologen stehen nicht Buddhisten, sondern Buddhismusforscher gegenüber, die intellektuell über eine brillante Kenntnis des Buddhismus verfügen, sich dessen Lebenszentrum aber nicht existentiell zu eigen gemacht haben. Sie sind nicht >der Andereı, den A. Bsteh ersucht, »sich selbst mitzuteilen - in dem, was ihn eigentlich bewegt, indem er der Lehre des Buddha folgt« (SzR 5, 9).

Zudem dominiert bei den beteiligten Buddhismusforschern die historischphilologische Orientierung. Der gelebte Buddhismus der Gegenwart in all seiner Vielfalt tritt hinter dem >klassischen religionsgeschichtlichen Zugang zurück, dabei wäre gerade er der eigentliche Partner eines Dialogs von Mitte zu Mitte. Diese Ausrichtung führt in den Gesprächen dazu, dass auch die christlichen Theologen eher traditionsbezogen argumentieren und weniger die Aneignungen der Tradition in der Gegenwart thematisieren. Ein so geführter Dialog fördert viele wertvolle Einsichten zutage, bleibt für die Identitätszentren der beteiligten Religionen aber harmlos.

Die gleiche Gesprächskonstellation begegnet auch im zweiten Band des Doppelwerks, in dem in den Vorträgen - nach einer Reflexion des Religionswissenschaftlers Hans-Jürgen Greschat auf exemplarische christlich-buddhistische Begegnungen in der Religionsgeschichte - christliche Theologen zu Wort kommen: Wilhelm Dupré stellt religionsphilosophische Überlegungen zum Thema »Erfahrung und Offenbarung« an. Der Alttestamentler Gottfried Vanoni arbeitet an der Gestalt des Gottesknechts die Themen Erwählung, Leiden und Stellvertretung auf - ohne jeden Bezug zum Buddhismus. In der Diskussion wird die Frage erörtert, wie sich das Mitleidsideal vor allem des Mahayana-Buddhismus (und damit die Gestalt des Bodhisattva) zum jesajanischen Gottesknecht verhält. Nach dem Karma-Gesetz gilt für das Schicksal eines Lebewesens ein strenger Tun-Ergehens-Zusammenhang. Die Übertragung der Früchte guter Taten auf andere Menschen ist nicht möglich. Doch schon früh - schon vor dem Mahayana-Buddhismus - wird (nach Steinkellner) dieses Prinzip für die Möglichkeit geöffnet, die Meriten guter Taten auch den verstorbenen Eltern zukommen zu lassen und damit eine Art Stellvertretung eingeführt. In der Figur des Bodhisattva tritt 
diese Möglichkeit dann ins Zentrum buddhistischer Spiritualität und Ethik. Durch den Überschuss des von ihm erwirkten Guten hebt er die schlechten karmischen Auswirkungen der Taten anderer auf und nimmt Einfluss auf ihren Heilsstatus. Wenn auch ein grundlegender Unterschied bleibt zwischen dem Gottesknecht, der aufgrund der und für die Schuld anderer Menschen leidet, ihre Schuld auf sich nimmt und damit tilgt, und dem Bodhisattva, der aus der Fülle seines guten Handelns karmische Heilskraft verteilt, so ist doch in beiden Fällen ein heilswirksames Eintreten für andere gegeben. Der Bodhisattva leidet nicht für andere. Er ist schon erlöst, zögert aber sein Eingehen ins Nirvana noch hinaus, um die Erlösung auch der anderen Lebewesen abzuwarten und dazu beizutragen. Von hier aus öffnet sich der Blick für die verschiedene Deutung des Leidens im Christentum und im Buddhismus: Nach buddhistischem Verständnis ist Leiden nicht auferlegt, sondern selbst zugezogen. Es kann nicht abgenommen, sondern muss selbst erlitten werden. Der Weg aus dem Leiden führt über die Wirkung guter Taten und hier - nicht schon im Ertragen des Leidens selbst beginnt die Möglichkeit der Stellvertretung. Sie kann darin bestehen, das Leiden anderer zu lindern, sie zum Tun des Guten zu befähigen oder auch ihnen die Wirkung eigener guter Taten zukommen zu lassen. Sie kann die Leidenden aber nicht vom Leiden selbst befreien.

Diese Gegenüberstellung führt zu einer Einsicht, die sich immer wieder bei interreligiösen Bezugnahmen aufdrängt: Es sind dies Analogien, bei denen - nach klassischer Definition der Analogie - die Unähnlichkeit die Ähnlichkeit überwiegt. Und doch helfen sie gerade darin, die Eigentümlichkeit bestimmter Motive klarer herauszuarbeiten und tiefer zu verstehen. Und sie führen immer wieder vor dir Frage, wie tief greifend die Unterschiede in der Sache wirklich sind. So gibt Heinrich Ott in der Diskussion zu bedenken, ob es sich bei dem "phänomenologischen Unterschied zwischen $\mathrm{Zu}-$ wendung des Verdienstes einerseits und stellvertretender Übernahme des Bösen andererseits« (SzR 6, 149f.) möglicherweise um zwei vermittelbare, weil nur perspektivisch konträre Ansichten handeln könnte, wogegen Herbert Frohnhofen und die Buddhismusforscher Nihom und Steinkellner dann wieder die tief greifenden Differenzen zwischen beiden Überlieferungskomplexen ins Feld führen.

Karl-Heinz Neufeld versucht in seinem Beitrag, zum Wesenskern des Christentums vorzustoßen und findet ihn in dessen Gemeinschaftscharakter gegenüber dem im Buddhismus vorherrschenden Individualismus. Der christlichen Konzentration auf Gottes- und Nächstenliebe stellt er die buddhistische Fokussierung auf erlösende Erkenntnis gegenüber. Die Wertung des Anderen sei im Buddhismus prinzipiell negativ, im Christentum prinzipiell positiv (SzR 6, 194). »Führt das nicht in eine Vereinzelung, die nichts als nur Isolation sein kann? (SzR 6, 200), so seine kritische Anfrage, die im anschließenden Gespräch kritische Gegenfragen auslöst. Der Verweis einiger Gesprächsteilnehmer auf die buddhistische Gemeinschaft des sangha und auf positive Wertungen des Anderen im Buddhismus widerlegen Neufelds allzu einfache und offensichtlich apologetisch motivierte Kontrastierungen.

Richard Schaeffler erörtert die nicht nur für die christlich-buddhistische Begegnung, sondern auch für das christliche Gottesdenken selbst zentrale Frage, ob die Letztwirklichkeit als personal-relationale Gottheit oder als impersonales Absolutum zu verstehen ist. Einerseits scheint die Vorstellung Gottes als eines personalen Gegenübers unverzichtbar, wenn zu ihm eine durch Liebe qualifizierte Beziehung bestehen soll. Andererseits steht diese Bestimmung immer in der Gefahr des Anthropomorphismus. Daher stellt Schaeffler seine Überlegungen unter die Leitfrage: »Kann Gott, wenn er auf rechte Weise als Person verstanden wird, zugleich als das Absolute ge- 
dacht werden?« (SzR 6, 242). Gott muss in dieser Weise gedacht werden, so lässt sich Schaefflers Antwort zusammenfassen, wenn sein Gottsein gewahrt bleiben soll. Die Überbetonung seiner Beziehung zur Schöpfung brächte die Gefahr mit sich, ihn in (liebender) Angewiesenheit auf die Schöpfung und damit in Abhängigkeit zu ihr zu sehen. Der Begriff des Absoluten legt den Akzent demgegenüber auf das Bedeutungsmoment der Losgelöstheit und damit der Aseität Gottes. Weil Schaeffler aber diesen Begriff von vornherein aus dem Bezugsrahmen des christlich-theistischen Gottesdenkens (mit Blick auf die griechisch-philosophische Tradition) und auf dieses hin entwickelt - als Freiheit des letztlich personal gedachten Gottes -, kommt es mit einer gewissen Notwendigkeit dazu, dass der Begriff des Absoluten sich »so weit von der Vorstellungswelt des Buddhismus (entfernt), dass es zweifelhaft erscheinen muss, ob er einem Gespräch zwischen Christen und Buddhisten auch dann noch dienen kann« (SzR 6, 257). Aus buddhistischer Sicht würde der Begriff des Absoluten eine pointiert nicht-theistische Auslegung erfahren müssen, etwa so, wie es Steinkellner andeutet, wenn er ihn in Beziehung zum Bild des Nirvana als Ort des Friedens setzt.

Elmar Klinger versucht, christologische Einsichten durch die Beschäftigung mit dem Buddhismus zu gewinnen. Er geht dabei von der buddhistischen Überwindung des Subjektseins der Person aus und fragt, ob sich durch eine Auflösung der theologischen Fokussierung auf die Person Jesu ein neuer Zugang zu ihm - zu seinem wahren Selbst - gewinnen ließe. Es schlägt vor, »Person« als eine Art Transparenzfolie zu verstehen, durch die hindurch das wahre Wesen der menschlichen >Person zum Vorschein kommt (zu dieser Einsicht hätte allerdings auch der Rückbezug auf die Ursprungsbedeutung des lateinischen Begriffs persona und seines griechischen Äquivalents prosopon geführt). Im Falle Jesu bedeutet dies: durch seine menschliche Personalität hindurch wird Gott sichtbar und dadurch erst ist sein wahres Selbst bestimmt. Eine zweite für die Christologie relevante Einsicht ergibt sich für Klinger aus buddhistischer Perspektive für die Beziehung zwischen der Person und der Lehre Jesu. In buddhistischen Jesus-Darstellungen tritt die Person Jesu ganz hinter seiner Lehre (besonders der Bergpredigt) zurück. Das, wofür Jesus gelebt hat und wofür er gestorben ist, bestimmt seine Identität. Seine »Person« ist als Ereigniszusammenhang zu verstehen, der zwischen Kreuz, Liebe und Mitgefühl ausgespannt ist. Dieser Ereigniszusammenhang ist - drittens - geschichtlich, als Weg zu deuten. Er ruft - wie der Achtfache Pfad Buddhas - auf den Weg der Nachfolge. Klingers Überlegungen, die im Fortgang seines Vortrags immer aphoristischere Züge annehmen, enthalten eine Reihe interessanter Impulse, die in den anschließenden beiden Arbeitskreisen aufgenommen werden. Dabei steht der Personbegriff im Mittelpunkt der Gespräche.

Heinrich Ott geht der Frage nach, wie das, »was eigentlich jenseits aller Erfahrung liegt, in unsere Erfahrung herein(kommt)« (SzR 6, 360). Vor allem die Mystik - von Ott weit gefasst als Erfahrungserkenntnis Gottes - kreist um die Erfahrung des Unerfahrbaren. Doch nur dort, wo das Absolute sich selbst erfahrbar macht, kann diese Erkenntnis zustande kommen. Und dazu ist nach Ott nur eine letztlich personal zu denkende Letztwirklichkeit in der Lage. Dass dies auch für den Buddhismus gilt, beweist die von Martin Buber beschriebene »glückliche Inkonsequenz« dieser Religion. Nicht in der Lehre, aber in der spirituellen Praxis des Mahayana und Volks-Buddhismus spiele das DU des Heiligen wieder eine wichtige Rolle (SzR 6, 367).

Lässt sich die buddhistische Rede vom Streben nach dem »Todlosen« mitten im Leben auch auf Christus und die Christen übertragen? In 10 Thesen entfaltet Herbert Frohnhofen Gedanken zur christlichen präsentischen Eschatologie, die nur terminologisch mit dem buddhistischen Begriff des Todlosen verbunden sind und daher ebenso 
in klassischer christlicher Auferstehungsbegrifflichkeit dargestellt werden könnten. Ebenso blickt auch Martin Karrer in seiner Aufarbeitung der neutestamentlichen Zeitvorstellungen und -erfahrungen nur ganz aus der Ferne in den Buddhismus hinüber, ohne sich auf eine wirkliche Auseinandersetzung mit den dort begegnenden Wahrnehmungen von Zeit einzulassen.

Bis auf einige Ausnahmen sind die in diesem Band zu Wort kommenden christlichen Theologen auf den ihnen vertrauten Denkwegen geblieben und haben sich der buddhistischen Lehre und Praxis nicht wirklich ausgesetzt. Manche reproduzieren altbekannte apologetische Schemata, andere stellen lediglich terminologische Anschlüsse her oder verweisen auf mögliche Analogien, die aber nur selten tiefer zu verstehen versucht werden. So wiederholt sich, was schon in den Referaten des ersten Bandes zu beobachten war: Wie die Buddhismusforscher kaum Neigung erkennen ließen, die von ihnen ausgebreiteten profunden Kenntnisse für die Begegnung mit der christlichen Theologie fruchtbar zu machen, so halten sich auch die christlichen Theologen mehrheitlich zurück, das Risiko interreligiöser Expeditionen einzugehen. Wie schon das Vorwort zu erkennen gibt (SzR 6, 9), bringen manche von ihnen kaum Kenntnis des Buddhismus und Begegnungserfahrungen mit seinen Anhängern mit und fühlen sich wenig vorbereitet, in den Dialog einzutreten. Das Projekt siedelt sich denn auch selbst im »Vorfeld des Dialogs« an. Der Leser bekommt einen Einblick in den offenen Lernprozess der Referenten, wobei allerdings nicht jeder von ihnen bereit ist, sich darauf auch offen einzulassen. Die Referate dienen als Impulse für die in den beiden Bänden dokumentierten Gespräche. Auch hier bleiben die Voten zwar nicht selten unvermittelt nebeneinander stehen, doch kommt es immer wieder zu spannenden Horizontöffnungen, unerwarteten Bezugnahmen und kreativen Revisionen, von denen starke Impulse für weiteres Nachdenken ausgehen: nicht nur hinsichtlich der christlich-buddhistischen Begegnung, sondern auch für die Entfaltung der christlichen Theologie selbst.

Die bisher in diesem Abschnitt genannten und besprochenen Monographien und Sammelbände waren der theologischen Auseinandersetzung mit je einer nichtchristlichen Religion gewidmet. Vereinzelt sind auch Bände erschienen, in denen religionstheologisch relevante Texte zu mehreren Religionen zusammengefasst sind. So enthält die Veröffentlichung einer Ringvorlesung, die 1997 in München stattgefunden hat, Beiträge zu den abrahamitischen, indischen, chinesischen und japanischen Religionen. Sie wurde 1999 von Venanz SChubert herausgegeben und trägt den Titel: »Religionen im Aufbruch? Identität - Konflikt - Toleranz«.

Der Band »Christliche Theologie und Weltreligionen. Grundlagen, Chancen und Schwierigkeiten des Dialogs heute« (hg. im Auftrag der Theologischen Fakultät Luzern von Hans J. Münk und der Theologischen Hochschule Chur von Michael Durst, 2003) enthält neben biblisch-theologischen (Hans Peter Mathys: Fremde Religionen in 
der Bibel), systematisch-theologischen (Helmut Hoping: Die Pluralität der Religionen und der Wahrheitsanspruch des Christentums) und ethisch-theologischen Beiträgen (Hans J. Münk: Die Weltreligionen im globalen Ethikdialog über Menschheitsfragen) eine historische Darstellung von Frieder Ludwig zur Islamwahrnehmung in Kirche und Mission sowie eine religionstheologische Besinnung auf die Beziehung zwischen christlicher Theologie und asiatischem Denken von Hans Waldenfels.

Beachtenswerte Beiträge zur Religionstheologie im Blick auf spezifische, einzelne Religionen betreffende Fragestellungen finden sich auch in den beiden Zeitschriften »Dialog der Religionen« (die von 1991 bis 1998 von Michael von Brück herausgegeben wurde) und in »Religionen unterwegs« (als Mitteilungen der Kontaktstelle für Weltreligionen in Österreich hg. von Petrus Bsteh, 1994ff.).

\section{Dogmatik im Kontext der Weltreligionen}

Hans-Martin Barth, Dogmatik. Evangelischer Glaube im Kontext der Weltreligionen. Ein Lehrbuch. Gütersloher Verlagshaus, Gütersloh 2001, 862 S. - REINHOLd Bernhardt / Georg Pfleiderer (Hgg.), Christlicher Wahrheitsanspruch - historische Relativität. Auseinandersetzungen mit Ernst Troeltschs Absolutheitsschrift im Kontext heutiger Religionstheologie (Christentum und Kultur 4). TVZ, Zürich 2004, 340 S. - Reinhold Bernhardt / Perry Schmidt-Leukel, Kriterien interreligiöser Urteilsbildung (Beiträge zu einer Theologie der Religionen 1). TVZ, Zürich 2005, 268 S. - Reinhold Bernhardt, Ende des Dialogs. Die Begegnung der Religionen und ihre theologische Reflexion (Beiträge zu einer Theologie der Religionen 2). Theologischer Verlag, Zürich 2006, 293 S. - Keith Ward, Religion and Community. Clarendon, Oxford 2000, 366 S. - Keith Ward, Religion and Creation. Clarendon, Oxford 1996, 351 S. - Keith Ward, Religion and Human Nature. Clarendon, Oxford 1998, 333 S. - Keith Ward, Religion and Revelation. A Theology of Revelation in the Worldks Religions. Clarendon, Oxford 1994, 350 S. - Keith Ward, The Case for Religion. Oneworld, Oxford 2004, VII + 246 S.

Nicht nur einzelne, für die Begegnung der christlichen Theologie mit einer bestimmten außerchristlichen Religion relevante Themen, sondern eine umfassende evangelische Dogmatik im Kontext der Weltreligionen entfaltet Hans-Martin Barth. Seine Absicht ist es, die Selbstbezüglichkeit einer theologischen Lehrentfaltung, die sich primär in Referenz zur vorausgehenden Überlieferung im Rahmen der abendländischen Geistesgeschichte explizierte, aufzubrechen zugunsten einer Theologie in Interaktion mit den Weltreligionen. Wenn B. sein 2001 erschienenes Werk als Lehrbuch aufgefasst sehen will, so erklärt sich das zunächst wohl daraus, dass Vorlesungen die Materialgrundlage der dogmatischen Teile bilden, entspricht aber auch der Zielsetzung, die herkömmlichen evangelisch-dogmatischen Lehrinhalte, wie sie sich üblicherweise in einem Kompendium finden, neu, eben in interreli- 
giöser Perspektive darzustellen. Nicht primär im Text liegt das Innovative, sondern im Kontext und in der Ausrichtung.

Nach den für ein solch avantgardistisches Projekt unabdingbaren Vorklärungen geht B. die Zentralthemen der christlichen Dogmatik durch, wobei er (in der Tradition Schleiermachers) vom Glauben ausgeht und im folgenden Teil »Die Begründung des Glaubens « fundamentaltheologische topoi verhandelt. Für die Entfaltung der materialdogmatischen Fragen wählt er ein trinitätstheologisches Strukturschema (was der grundlegenden Bedeutung der Trinitätstheologie für seinen religionstheologischen Ansatz insgesamt entspricht) und fügt die loci »Welt und Mensch « (Schöpfungstheologie, theologische Anthropologie), "Erlösung" (Soteriologie, inkl. Ekklesiologie) und »Hoffnung über den Tod hinaus« (Eschatologie) an.

Jedes der Kapitel ist dreigliedrig aufgebaut: Nachdem die evangelische Position zum jeweiligen Themenbereich aus der Sicht des Autors dargestellt worden ist, setzt er sie in Beziehung zu den vergleichbaren Aussagen von Judentum, Islam, Hinduismus und Buddhismus und diskutiert im dritten Teil die sich daraus für den christlichen Glauben ergebenden Herausforderungen. Dabei wird keine metareligiöse Zentralperspektive angestrebt, sondern die Standortgebundenheit an die christlichen Bekenntnisinhalte vorausgesetzt und durchgehalten. B. geht es nicht um einen religionsphänomenologischen oder -geschichtlichen Vergleich, schon gar nicht um eine Wertung, auch nicht um harmonisierende Synthesen oder um eine Apologetik, welche die Lehren der nichtchristlichen Religionen mit christlichen Antworten versieht, wie es bei Hans Küng (in dem von ihm mit-hg. Band »Christentum und Weltreligionen«, 1984) der Fall war. Angestrebt wird vielmehr eine neue Selbstwahrnehmung des christlich-evangelischen Glaubens mit dem Ziel einer vertieften Erschließung seiner Inhalte.

Dass schon ein solches Konzept theologische Voraussetzungen in sich schließt, die eine Revision bestimmter traditioneller Auffassungen nach sich ziehen müssen, liegt auf der Hand und B. gibt sich darüber Rechenschaft. So legt er schon im Vorwort seine Grundüberzeugung offen, »daß hinter den zu untersuchenden Traditionen - in einer wie verborgenen Weise auch immer - der dreieine Gott am Werk ist« (8). Nur wenn unterstellt wird, dass Gott auch durch die Medien der nichtchristlichen Religionen zur Christenheit sprechen will (49), kann es eine »Theologie der Religionen« im Sinne eines genitivus subjectivus geben, d.h. eine solche, in der die Überlieferungsquellen und -ströme der nichtchristlichen Religionen als Subjekte der Theologie behandelt werden (50, Zitat Waldenfels).

Ein solcher Ausgangspunkt muss Konsequenzen für das christliche Offenbarungsverständnis haben. Angedeutet finden sie sich in B.s modifizierender Fortschreibung der ersten Barmer These: »Die Kirche darf sals Quelle ihrer Verkündigungく zwar nicht raußer und neben diesem einen Wort Gottes«, wohl aber unter diesem einen Wort Gottes rauch noch andere Ereignisse und Mächte, Gestalten und Wahrheiten als Gottes Offenbarung anerkennen« (169). Die heiligen Schriften der nichtchristlichen Religionen sind nach B. aus dem providentiellen Handeln Gottes hervorgegangen und können zur Ausdeutung der Heiligen Schrift der Christen herangezogen werden. Dazu sind sie »von Jesus Christus her und auf ihn hin zu lesen« (221, siehe auch 200). In der Mitte der Schrift, in Christus, begegnet die normative Selbsterschließung des dreieinigen Gottes. Auf sie können und müssen nicht nur die Aussagen der biblischen Überlieferungen Alten und Neuen Testaments, sondern auch die der nichtchristlichen Offenbarungsquellen bezogen werden. Damit ist ein offenbarungstheologischer Inklusi- 
vismus anvisiert, der die Spitze des hermeneutischen Zirkels im Zentralinhalt des christlichen Glaubens einsetzt (220). Wenn B. feststellt, die biblische Botschaft transzendiere die nichtchristlichen Vermittlungswege von Wahrheitsgewissheit (214), dann ist das allerdings aus der Sicht der Religionen auch für deren Botschaften zu sagen. In jeder der Offenbarungsreligionen findet sich die religionskritische Unterscheidung zwischen dem transzendenten Bezugspunkt der Offenbarung und ihren religiösen Manifestationen.

Auf diese Weise entsteht bei B. - wenn auch nicht beabsichtigt, doch wohl aber unvermeidlich - eine Überordnung der christlichen über die nichtchristlichen Überlieferungsgehalte. Die Trinitätslehre erscheint als »formales Integrationsangebot«, in das sich Formen nichtchristlicher Offenbarung raufheben lassen (155f.): »Was sich in den nichtchristlichen Religionen auf verschiedene Elemente zu verteilen scheint, erweist sich nach dem Verständnis des Christentums als zusammengehörig« (156). Eine ähnliche Integrationsfunktion wird der Heiligen Schrift der Christen zugeschrieben. In ihr »verbinden sich drei Elemente miteinander, die in den außerchristlichen Religionen ... nebeneinander stehen: Die aktuelle Wirksamkeit des göttlichen Geistes, das Zeugnis der Schöpfung und das der Geschichte« (216). Dass die Bestimmung dieser drei Elemente und das Anliegen, sie zu integrieren, christlichen Präferenzen entspringen, liegt auf der Hand.

Wenn B. sich der Perspektivität solcher Aussagen auch immer bewusst bleibt und mit diesem an die christliche Wahrheitsgewissheit gebundenen Inklusivismus kein sobjektiver Überlegenheitsanspruch der christlichen Glaubenswahrheit verbunden ist, so bleibt doch die Frage, ob die Religionen hier wirklich zu Subjekten der Theologie erhoben werden - und vor allem: ob ihre Überlieferungen zu wirklichen Herausforderungen für die Theologie werden. Die dogmatischen Lehrinhalte bleiben von der Begegnung mit den außerchristlichen Traditionen doch relativ unberührt. Ihre Auslegung steht unabhängig von dieser Begegnung fest und wird als solche dann zu den Lehrund Lebensformen der Religionen in Beziehung gesetzt. Damit aber kommt der Entdeckungszusammenhang, den eine Dogmatik im Kontext der Weltreligionen bieten könnte, nicht wirklich zum Tragen. Dem Kontext wird letztlich wenig Einfluss auf den Text zugestanden. Eine solche Öffnung müsste keineswegs notwendig zu einer Anpassung christlicher an nichtchristliche Überzeugungen führen, sondern könnte zu dem beitragen, was B. anstrebt: eine vertiefende Wiederaneignung des spezifisch Christlichen.

Doch bei allen kritischen Anfragen kann kein Zweifel daran bestehen, dass B. mit seiner Dogmatik im Rahmen der deutschsprachigen religionstheologischen Debatte ein Grenzen sprengendes und neue Horizonte eröffnendes Werk vorgelegt hat, das wichtige Impulse zu weiteren Schritten in Richtung einer religionsdialogisch sich entfaltenden christlichen Theologie gibt.

Im englischsprachigen Raum sind die Versuche, Themen der christlichen Glaubenslehre im Kontext der außerchristlichen Religionen zu entfalten, z.T. schon weiter fortgeschritten. Exemplarisch verweise ich lediglich auf die Arbeiten von Keith WARD aus Oxford: »Religion and Revelation« (1994), »Re- 
ligion and Creation« (1996), »Religion and Human Nature« (1998), »Religion and Community« (2000), sowie »The Case for Religion« (2004).

Am Ende dieses Literaturberichts erlaube ich mir, noch zwei von mir mitherausgegebene Sammelbände anzuzeigen: Die Beiträge zu einem Forschungssymposium, das anlässlich des 100. Publikationsjubiläums von Ernst Troeltschs Schrift »Die Absolutheit des Christentums und die Religionsgeschichte« (1902/1912) stattfand, sind in dem Band »Christlicher Wahrheitsanspruch - historische Relativität. Auseinandersetzungen mit Ernst Troeltschs Absolutheitsschrift im Kontext heutiger Religionstheologie (hg. von Reinhold Bernhardt und Georg Pfleiderer, 2004) veröffentlicht. Den Themen der Absolutheitsschrift entlanggehend werden unterschiedliche Konzeptionen aktueller Religionstheologie in kritischer Auseinandersetzung mit Ernst Troeltsch entwickelt. Beteiligt an diesem Projekt waren außer den Initiatoren und Herausgebern: Michael Bongardt, Johann Hinrich Claussen, Friedrich Wilhelm Graf, Martin Hailer, Michael Hüttenhoff, Arie L. Molendijk, Friederike Nüssel, Hartmut Ruddies, Perry Schmidt-Leukel, Brent W. Sockness und Folkart Wittekind.

Mit diesem Kreis wurden zwei Strömungen der gegenwärtigen religionstheoretischen und -theologischen Debatte zusammengeführt, die man als »Theologie der Religion« (im Singular) und »Theologie der Religionen« (im Plural) etikettieren kann. Die Vertreter der ersten Richtung entwickeln die (systematische und praktische) Theologie als Theorie gelebter Religion, wobei sie nicht selten an Exponenten der deutschsprachigen Theologie des 19. und 20. Jh.s (kritisch) anknüpfen. Religion ist Lebensdeutung und muss sich daraufhin durchleuchten lassen. Die zweite Richtung versteht Religionstheologie - wie in diesem Literaturbericht vorausgesetzt - als systematischtheologische Reflexion auf die Beziehungen zwischen der christlichen und den außerchristlichen Religionen, ihren Offenbarungsquellen, Lehr- und Praxisformen. Sie stellt sich der Aufgabe, die Pluralität der Religionen theologisch zu bearbeiten. In der Begegnung dieser beiden Strömungen haben sich gegenseitige Befruchtungen ergeben.

Im Herbst 2005 erschien eine - ebenfalls auf eine Tagung zurückgehende - Aufsatzsammlung unter dem Titel: »Kriterien interreligiöser Urteilsbildung" (hg. von Reinhold Bernhardt und Perry Schmidt-Leukel) als erster Band der neu gegründeten Reihe »Beiträge zu einer Theologie der Religionen«. Dieser Band stellt sich dem Problem einer reflektierten und differenzierten Urteilsbildung, dessen Bearbeitung in der religionstheologischen Diskussion immer wieder angemahnt wurde und wird. Ganz offensichtlich besteht die Notwendigkeit, nicht nur verstehen-wollend in den Dialog mit anderen Religionen zu gehen, sondern auch kritisch prüfend. Zu viele der 
angeblichen Heilswege haben unheilvolle Früchte getragen, ihre Anhänger in einen individuellen oder kollektiven Heilsegoismus geführt und Feindschaft gegenüber Andersglaubenden gesät - vor allem gegenüber Abweichlern innerhalb der eigenen Religion. Im weiten und diffusen Feld der Religionen bedarf es der kritischen Prüfung, gerade um (Paulus in 1Thess 5, 21 folgend) das Gute zu erkennen und anzuerkennen. Die Autoren dieses Bandes (neben den Herausgebern: Stephan Peter Bumbacher, Günther Gebhardt, Michael Hüttenhoff, Armin Kreiner, Claude Ozankom, Andreas Renz, Klaus von Stosch, Ulrich Winkler) zeichnen nach, wie interreligiöse Urteilsprozesse in der Religionsgeschichte verlaufen sind, erörtern Grundsatz- und Methodenfragen der Kriterienbestimmung und stellen materiale Kriterien zur Diskussion. Als Band 2 dieser Reihe ist 2006 die Monographie »Ende des Dialogs? Die Begegnung der Religionen und ihre theologische Reflexion« von REINhold Bernhardt erschienen, die in drei Teilen Grundfragen des Dialogs, der Hermeneutik und der Theologie der Religionen erörtert. 